\title{
Sellar surprises: a single-centre experience of unusual sellar masses
}

\author{
Kunal Thakkar ${ }^{1}$, Swati Ramteke-Jadhav ${ }^{1}$, Rajeev Kasaliwal' ${ }^{2}$ Saba Samad Memon' ${ }^{1}$, Virendra Patil', Puja Thadani ${ }^{1}$, \\ Nilesh Lomte ${ }^{1}$, Shilpa Sankhe ${ }^{3}$, Atul Goel ${ }^{4}$, Sridhar Epari ${ }^{5}$, Naina Goel ${ }^{6}$, Anurag Lila ${ }^{1}$, Nalini S Shah $^{1}$ and \\ Tushar Bandgar ${ }^{1}$
}

'Department of Endocrinology, Seth G S Medical College \& KEM Hospital, Mumbai, India 2Department of Endocrinology, Mahatma Gandhi Medical College \& Hospital, Jaipur, India ${ }^{3}$ Department of Radiology, Seth G S Medical College \& KEM Hospital, Mumbai, India

${ }^{4}$ Department of Neurosurgery, Seth G S Medical College \& KEM Hospital, Mumbai, India

${ }^{5}$ Department of Pathology, Tata Memorial Centre, Mumbai, India

${ }^{6}$ Department of Neuropathology, Seth G S Medical College \& KEM Hospital, Mumbai, India

Correspondence should be addressed to V Patil: viru.patil33@gmail.com

\begin{abstract}
Background: Most common incidentally detected sellar-suprasellar region (SSR) masses are pituitary adenomas, followed by craniopharyngioma, rathke's cleft cyst, hypophysitis, and meningioma. Besides these, certain unusual SSR lesions can sometimes present as diagnostic challenges, where diagnosis is often made post-operatively on histopathology, the pre-operative suspicion of which might have influenced the management strategies. Series describing such masses are few.

Objective: To present clinical, biochemical, and radiological characteristics and management outcomes of rare SSR lesions other than pituitary adenomas, craniopharyngioma, rathke's cleft cyst, hypophysitis, and meningioma.

Design, setting, patients: Retrospective case record analysis of patients with uncommon SSR masses (from January 2006 to December 2016).

Results: Our series consisted of ten patients, five with neoplastic and five with nonneoplastic lesions. Neoplastic masses included granular cell tumor $(n=2)$, astrocytoma $(n=1)$, malignant peripheral nerve sheath tumor (MPNST, $n=1)$, and metastasis from occult papillary carcinoma of thyroid $(n=1)$, while non-neoplastic masses were aspergillus abscess $(n=1)$, sterile abscess $(n=1)$, and tubercular abscess $(n=1)$, aneurysm of left internal carotid artery $(n=1)$, and ruptured dermoid cyst $(n=1)$. All patients (except one) presented with headache and/or visual disturbance. Only one patient had acromegaly while most others had hypopituitarism. We describe detailed MRI characteristics of each of the lesion. Seven patients underwent trans-sphenoidal surgery. Post-operatively, five patients had permanent diabetes insipidus, while two patients died in early post-operative period.

Conclusion: Our series expand the differential diagnostic considerations of SSR lesions. Most of the rare SSR masses present with symptoms of mass effects and hypopituitarism. Except for some non-neoplastic lesions like sellar abscesses, aneurysms, and dermoid cysts which can have some specific imaging characteristics that can provide clue to preoperative diagnosis, most of the other neoplastic masses have overlapping radiological features, and pre-operative suspicion remains difficult.
\end{abstract}

\section{Key Words}

- sellar suprasellar region

- granular cell tumor

- malignant peripheral nerve sheath tumor

- aneurysm

- abscess

- astrocytoma https://ec.bioscientifica.com

https://doi.org/10.1530/EC-19-0497 (c) 2020 The authors Published by Bioscientifica Ltd

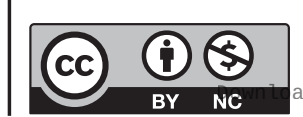

This work is licensed under a Creative Commons Attribution-NonCommercial 4.0 International License. ded from Bioscientifica.com at 04/26/2023 01:07:39PM
Endocrine Connections (2020) 9, 111-121 


\section{Introduction}

Neuro-radiological detection of masses in the sellarsuprasellar region (SSR) is a common cause of referral in endocrine practice. While some of them are 'sought' on neuro-imaging done for clinical presentation of specific hormone excess syndromes, most others are 'incidentally' detected on neuro-imaging done for symptoms of mass effect. Since SSR harbors tissues of diverse cytogenetic origin, a remarkable variety of both pituitary and non-pituitary masses of neoplastic as well as non-neoplastic etiologies can be found in this region (1). Pituitary adenomas are the commonest SSR tumors accounting for $85 \%$ of sellar masses (2). Amidst the non-adenoma masses, other common sellar lesions include craniopharyngioma (CR, 12-16\%), rathke's cleft cyst (RCC, 28-33\%), lymphocytic hypophysitis (LyH, 5\%), and meningioma (3-8\%) $(3,4)$. These lesions often have characteristic radiological appearance suggesting pre-operative diagnosis. However, besides these common lesions, certain 'rare SSR lesions' are sometimes encountered, whose diagnosis may be missed pre-operatively $(5,6)$. Herein we present clinical, biochemical, and radiological characteristics as well as management outcomes of rare SSR lesions other than pituitary adenomas, CR, RCC, LyH, and meningioma. With this report, we attempt to expand the spectrum of different SSR masses other than the commonly known lesions.

\section{Methods}

Retrospective case record analysis was undertaken for patients with uncommon SSR masses, managed at our centre in last decade, during a period between January 2006 and December 2016. For this retrospective study, ethics committee approval and waiver of informed consent was obtained from Institutional Ethics Committee II, Seth G S Medical College and KEM Hospital, Mumbai. Out of 1138 SSR lesions identified, pituitary adenomas $(n=928,81.6 \%)$, CR $(n=105,9.2 \%)$, LyH $(n=53,4.7 \%)$, RCC $(n=33,2.9 \%)$, and meningioma $(n=9,0.8 \%)$ constituted majority of the lesions while ten other 'rare SSR lesions' were identified. The following data, at baseline and on serial follow-up, was recorded for these ten patients-clinical features, hormonal investigations, imaging (MRI) details, the management modalities, and outcomes. The methodological details about imaging technique, hormonal evaluation, and definition of hypopituitarism have been described previously (7).

\section{Results}

Our series consisted of ten patients, five females and five males. Mean age of patients was 42 (range 16-65) years. Five patients had neoplastic masses while five had non-neoplastic lesions. The etiological diagnosis of neoplastic masses were granular cell tumor $(n=2)$, astrocytoma $(n=1)$, malignant peripheral nerve sheath tumor (MPNST, $n=1$ ), and metastasis from occult papillary carcinoma of thyroid $(n=1)$. The nonneoplastic masses consisted of aspergillus abscess $(n=1)$, sterile abscess $(n=1)$, and tubercular abscess $(n=1)$, aneurysm of left internal carotid artery $(n=1)$, and ruptured dermoid cyst $(n=1)$. The diagnosis was ascertained on the basis of histopathology in seven patients. In the remaining three patients, who did not undergo surgery, diagnosis was ascertained as follows: 1) case 3, patient with tubercular abscess was diagnosed based on characteristic findings on cerebrospinal fluid analysis (lymphocytic pleocytosis with high adenosine deaminase levels) and therapeutic response to antitubercular antibiotics; 2) case 5, patient with aneurysm of internal carotid artery was diagnosed on the basis of findings on digital subtraction angiography; and 3) case 4 , patient with ruptured dermoid cyst was diagnosed on the basis of characteristic radiological findings of periventricular fat globules.

The clinical, biochemical, and radiological features are summarized in Figs 1, 2, 3, 4 and Table 1.

All patients (except case 6) presented with headache and/or visual disturbance of varying duration, ranging from being acute in onset to 18 months. Patient 6 with granular cell tumor had indolent presentation with short stature and pubertal arrest. Another patient with granular cell tumor (case 7) had additional symptoms of secondary amenorrhea and unappreciated acromegaloid features. Fever was the associated symptom in two of three patients with abscesses. Hypopituitarism was seen in all except one patient (case 4). Cortisol and gonadotropin axes were the commonest axes involved followed by thyroid axis. Three patients had elevated prolactin levels. Seven patients underwent transsphenoidal surgery (TSS). Post-operatively, five patients had permanent central diabetes insipidus (DI) while two patients (case 7 with granular cell tumor and case 9 with MPNST) died in early post-operative period. 

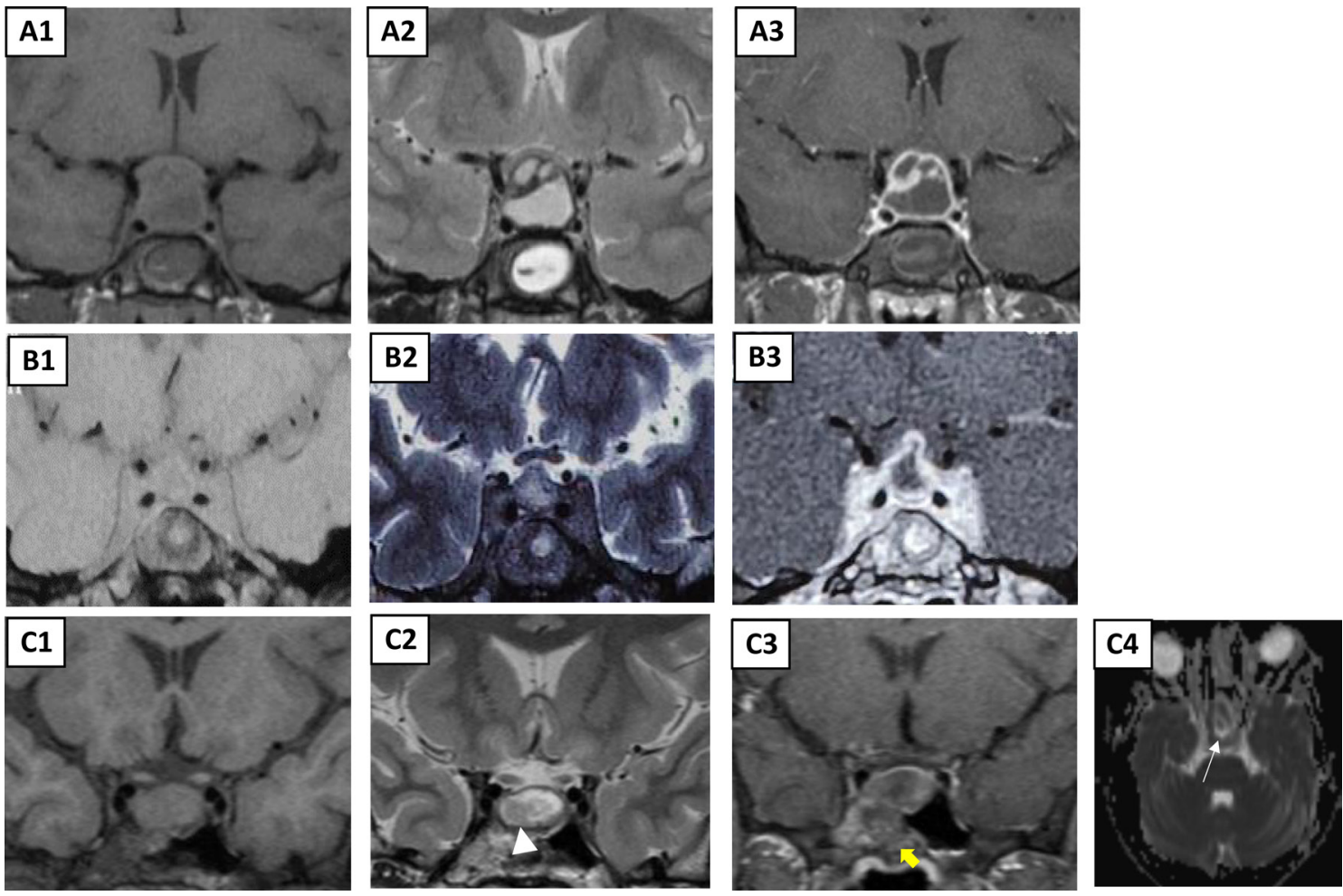

\section{Figure 1}

MRI features of cases 1, 2, and 3 (pituitary abscesses). Case 1 (sterile abscess): A1, hypointense on T1Wl; A2, hyperintense on T2Wl; A3, rim enhancement with loculations on post contrast image. Case 2 (tubercular abscess): B1, isointense on T1Wl; B2, hyperintense on T2Wl; B3, rim enhancement with shaggy borders on post contrast image. Case 3 (Aspergillus abscess): C1, isointensity on T1WI; C2, T2WI showing central area of intermediateintensity surrounded by hyperintensity (shown by arrowhead); C3, peripheral rim enhancement with extension of the lesion in sphenoid sinus (shown by yellow arrow); C4, 'target lesion' on diffusion weighted imaging (white arrow).

The detailed clinical course of individual patients is discussed below and summarized in Table 1 .

\section{Discussion}

Apart from pituitary adenomas and other common lesions, certain SSR lesions with uncommon etiologies can sometimes present as un-expected diagnoses, often made on post-operative histopathological examination. We present a series of ten patients with such rare SSR lesions. With ten such lesions out of 1138 SSR lesions managed at our centre in last decade, the prevalence of such lesions is $0.1 \%$ in our series, signifying the rarity of these lesions. There are only two similar series previously described in literature, both reporting spectrum of etiologies remarkably different from that found in our centre $(5,6)$. In a German neurosurgical series, Petrakakis et al. described 20 patients with rare SSR lesions of eight different etiologies (5). While xanthogranulomas $(n=6)$ were the commonest tumors in their series, other etiologies included metastases, colloid/ epidermal cysts, pilocytic astrocytomas, gangliocytoma, lymphocytic hypophysitis, and concomitant germ cell tumor/rhabdomyosarcoma. Recently, Abushamat et al. described nine patients with such 'very unusual' lesions from their extensive experience of treating 7000 patients with SSR tumors (6). Their series consisted of three patients with diffuse large B cell lymphoma and one patient each with sellar neurosarcoid, MPNST, fibrosarcoma, and granulomatosis with polyangiitis and two patients with pituitary adenomas having foci of chronic lymphocytic lymphoma and ectopic nerve fascicles. Such series are important since they expand the differential diagnostic considerations of SSR lesions, the pre-operative suspicion of which might bear influence on further surgical management and follow-up strategies. We discuss each of the diagnosis seen in our series in details.

\section{Non-neoplastic lesions}

\section{Pituitary abscesses (cases 1, 2, and 3)}

With three patients, pituitary abscesses were the most frequent lesions seen in our series. Two patients, those with sterile and tubercular abscesses, had primary https://ec.bioscientifica.com https://doi.org/10.1530/EC-19-0497 (c) 2020 The authors Published by Bioscientifica Ltd

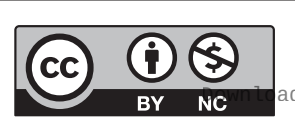

This work is licensed under a Creative Commons Attribution-NonCommercial 4.0 International License. ded from Bioscientifica.com at 04/26/2023 01:07:39PM 

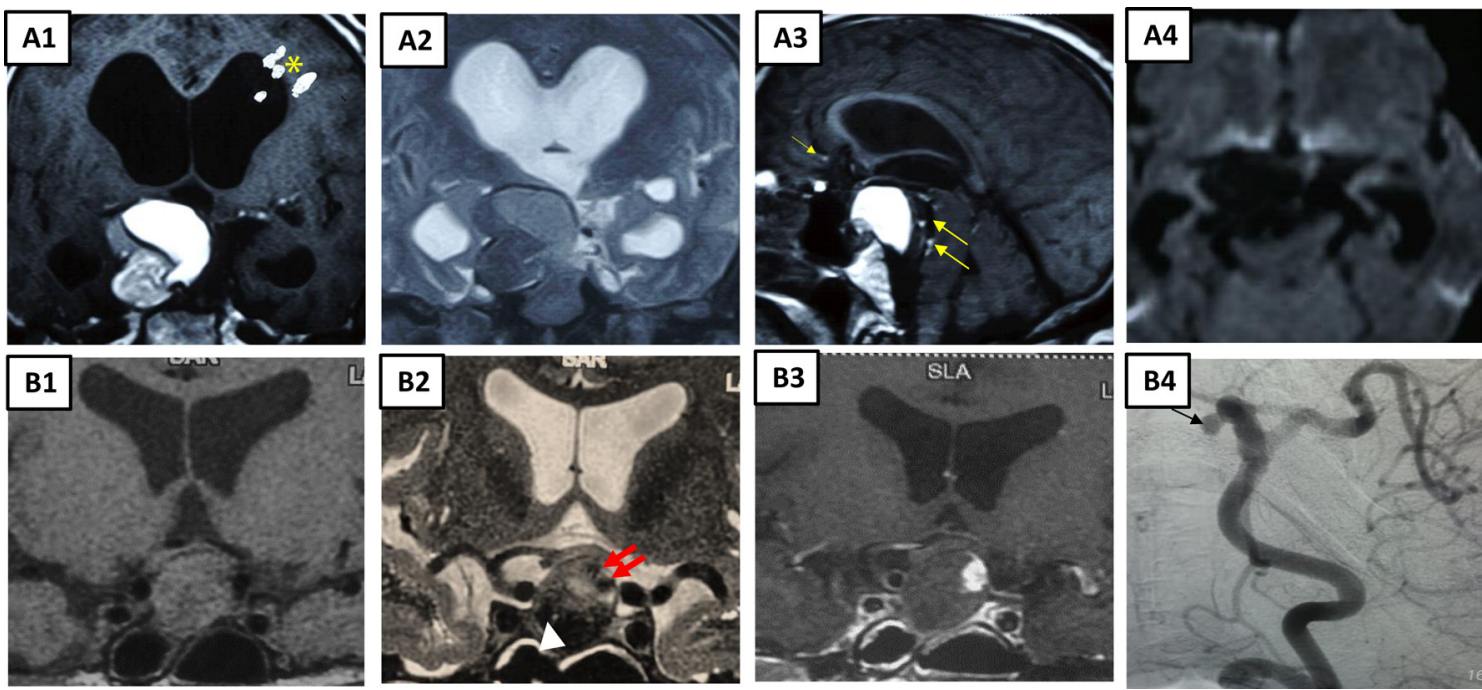

Figure 2

MRI features of cases 4 and 5 (non-infective, non-neoplastic SSR lesions). Case 4 (ruptured Dermoid cyst): A1, coronal T1WI showing heterogeneously hyperintense areas suggesting fat content; $A 2$, mass is iso to hypointense on coronal T2WI; $A 3$, sagittal T1WI showing multiple T1 hyperintensities in subarachnoid spaces (shown by yellow arrows) and also along left lateral ventricle (yellow asterisk in A1) suggestive of rupture of dermoid cyst; A4, axial DWI showing no restriction in the lesion. Case 5 (sellar aneurysm): B1, coronal T1WI showing heterogeneously isointense mass; B2, coronal T2WI showing areas of hypointensity on left superior aspect (flow voids, red arrows) and inferior aspect (white arrow head), probably due to organised blood in thrombus; B3, coronal postcontrast T1WI showing intense enhancement in left superior aspect of lesion (corresponding to flow void areas on T2WI) suggestive of patent lumen of aneurysm. Also note the non-enhancement in the rest of the mass, suggestive of thrombus; B4, left carotid artery angiogram on DSA showing inferomedially directed wide neck aneurysm (black arrow) of left supraclinoid ICA near the origin of ophthalmic artery.

abscesses while patient with aspergillus abscess had secondary abscess, occurring in setting of previous surgery for craniopharyngioma. Headache and hypopituitarism were present in all patients. Two patients had fever, while patient with aspergillus abscess did not have fever. Patient with tubercular abscess also had history of significant weight loss. Recently, Gao et al. reported the largest series of 66 patients with pituitary abscesses (8). Our patients' symptomatology was similar to that described in their series.
Hypopituitarism (81.8\%) followed by headache $(69.7 \%)$ were the most common features at presentation in their series, while systemic symptoms of fever and leukocytosis were uncommon (43.9\%). In our series, all patients had characteristic MRI features of T1 iso-hypointense signals, $\mathrm{T} 2$ hyperintense signals, and central necrotic areas with peripheral rim contrast enhancement (Fig. 1). Though characteristic, such typical radiological features were seen in $65 \%$ of patients in the series reported by Gao et al. (8).
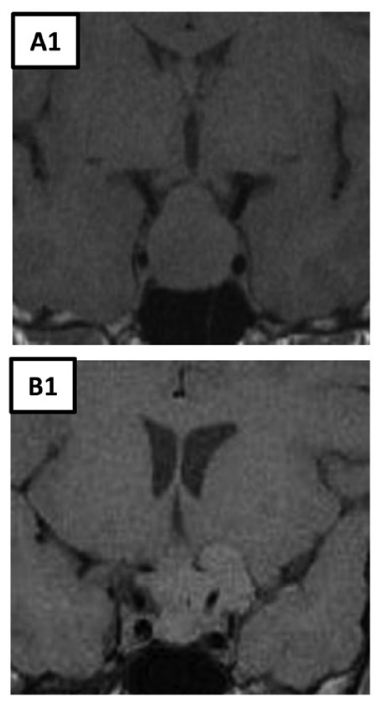
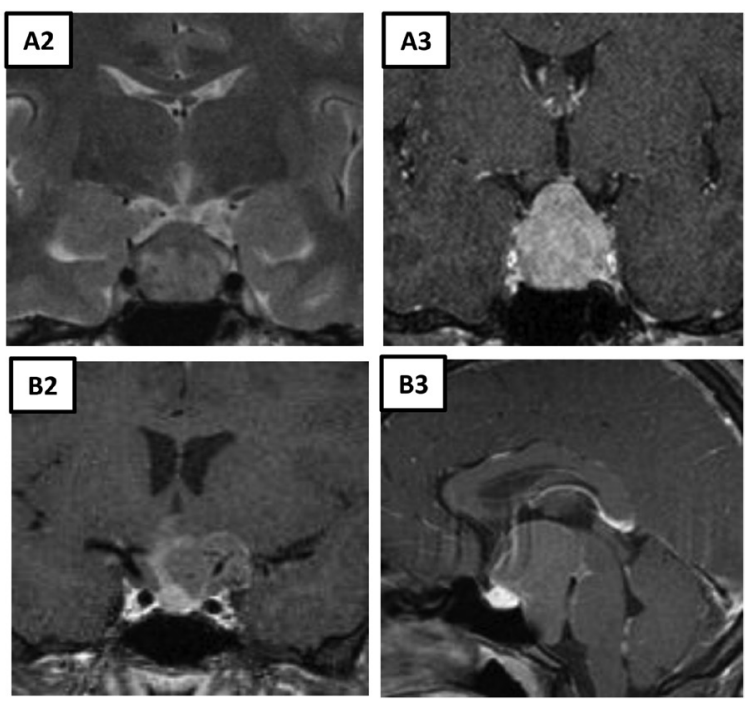

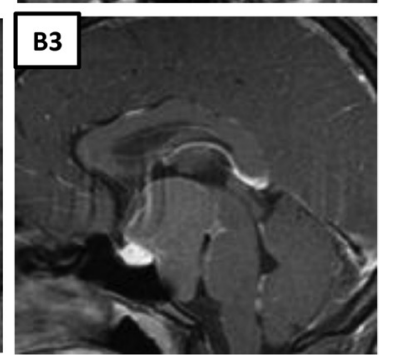

\section{Figure 3}

Features of granular cell tumors (cases 6 and 7) on MRI imaging. Case 6: A1, coronal T1WI showinghomogenously isointense rounded sellarsuprasellarmass; A2, coronal T2WI showingmass to be heterogeneously isointense; A3, coronal T1WI post contrast image shows hyperenhancing mass. Note that the pituitary is not seen separately from the mass. Case 7: B1, coronal T1WI, irregularly shaped isointense sellar-suprasellar mass; B2, coronal T1WI post contrast image; B3, sagital T1WI post contrast image. Both show hypoenhancing mass as compared to normal pituitary, which is clearly seen separate from the mass. https://ec.bioscientifica.com https://doi.org/10.1530/EC-19-0497 (c) 2020 The authors Published by Bioscientifica Ltd

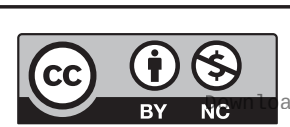

This work is licensed under a Creative Commons Attribution-NonCommercial 4.0 International License. ded from Bioscientifica.com at 04/26/2023 01:07:39PM 

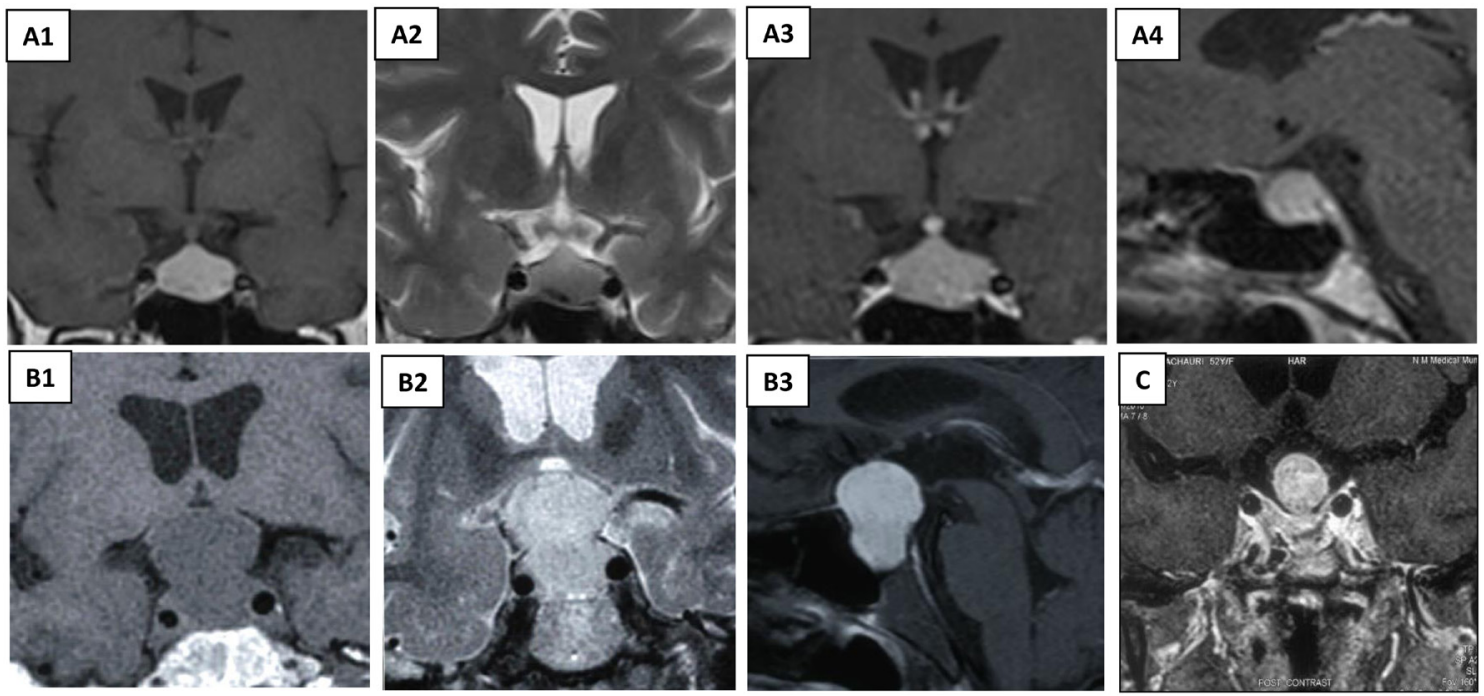

Figure 4

Features of other neoplastic sellar masses (cases 8, 9, and 10) on MRI imaging. Case 8 (sellar astrocytoma): A1, coronal T1WI; A2, coronal T2WI, the sellar mass is solid, hyperintense on T1WI and iso-hypointense on T2WI (suggestive of acute haemorrhage); A3, coronal T1WI post contrast image; A4, sagittal T1WI post contrast image. Mass shows no further enhancement due to very high baseline intensity on T1WI. Also note the predominant sellar location of the mass. Case 9 (MPNST): B1, coronal T1WI; B2, coronal T2Wl; B3, sagittal T1WI post contrast image. Well defined sellar-suprasellar mass is isointense on $\mathrm{T} 1 \mathrm{Wl}$, hyperintense on $\mathrm{T} 2 \mathrm{Wl}$, and shows homogenous intense enhancement on post contrast imaging. Case 10 (sellar metastasis): C, coronal T1WI post contrast image showing round predominantly suprasellar mass with heterogenous contrast enhancement, seen separate from pituitary.

Rest of the patients exhibited heterogenous intensities on T1W, T2W, and contrast enhanced scans. Apart from these, two additional MRI features are considered to be specific for cerebral aspergillosis: 1) 'target ADC lesions' on diffusion weighted images (DWI); and 2) central intermediate signal corresponding to coagulative fungal necrosis, surrounded by hyperintense signal corresponding to vasogenic edema, on T2WI (9). Our patient with aspergillus abscess (case 3 ) had the target ADC lesion on DWI (Fig. 1C4) and an area of hypointensity partially surrounded by hyperintensity on T2WI (Fig. 1C2).

Although pituitary abscesses, if diagnosed correctly, can be treated medically alone, trans-sphenoidal surgery is still necessary as it provides definitive diagnosis and allows for pus drainage thus relieving symptoms. Two of our patients (cases 1 and 3) underwent TSS, which relieved the symptoms of headache. Case 1 had drainage of frank pus on TSS, which was negative on microbiological cultures signifying the diagnosis of sterile abscess. Case 3 had characteristic histopathological evidence of aspergillus infection (Fig. 5A). Follow-up MRI showed no residual or recurrence of lesions. Based on signs of meningeal inflammation and characteristic cerebrospinal fluid analysis, patient with tubercular abscess (case 2) was managed conservatively with anti-tubercular drugs, to which he showed complete clinical response. However, all three of our patients did not have recovery of pituitary function and are on pituitary hormone replacements, which is consistent with reports of poor recovery of pituitary functions in patients with pituitary abscesses (8). Summarizing, presence of fever, headache, hypopituitarism, and characteristic cystic lesion on MRI might help suspect pituitary abscess pre-operatively.

\section{Ruptured dermoid cyst}

Dermoid cysts are congenital non-neoplastic ectodermal inclusion cysts lined by stratified squamous epithelium. Unlike epidermoid cysts, presence of dermal appendages like sweat and sebaceous glands as well as exodermal structures like hair in the lining epithelium are the characteristic feature of dermoid cysts (10). Lipid-rich secretions from these glands result in the characteristic T1W hyperintense signals typically described for dermoid cyst. Intracranial dermoid cysts are often midline structures, the commonest location being suprasellar cistern followed by posterior fossa. Due to slow-growing nature of these cysts, patients are either asymptomatic or present with features of mass effect. Rupture of a dermoid cyst is a rare but well-described phenomenon. In an extensive review, El-Bahy et al. described a series of 51 patients with ruptured intracranial dermoid cysts comprising two patients from their centre and 49 from world literature (11). They reported headache
This work is licensed under a Creative Commons Attribution-NonCommercial 4.0 International License. ded from Bioscientifica.com at 04/26/2023 01:07:39PM 

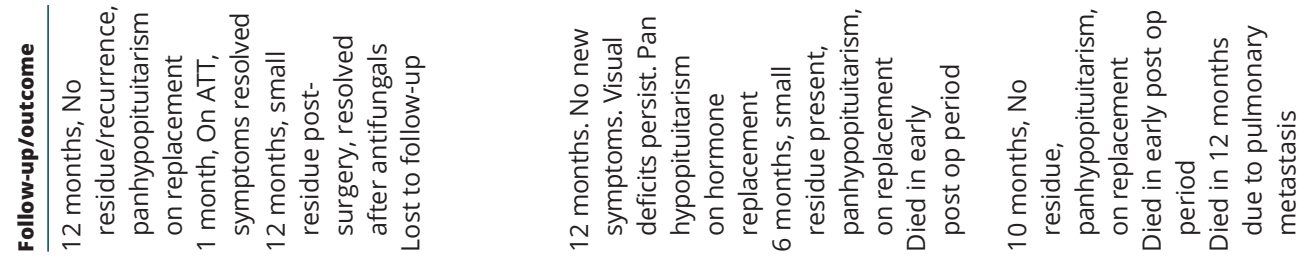

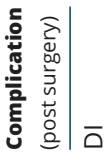

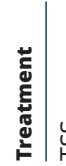

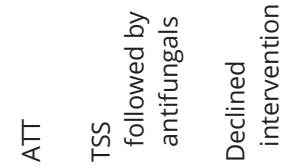

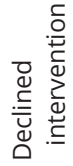

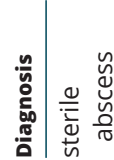

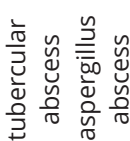

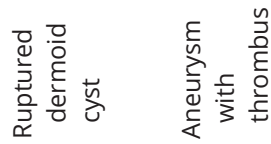

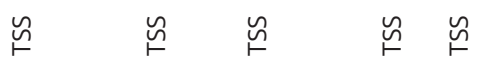

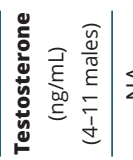

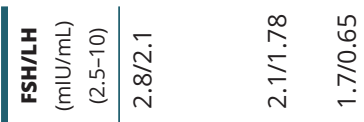

$\stackrel{\infty}{\stackrel{\infty}{*}}$

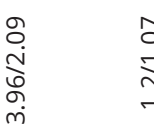

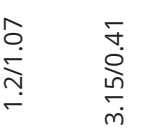

ஸ़่

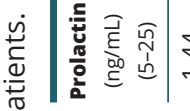

$\stackrel{n}{r} \stackrel{m}{m}$

$\stackrel{\text { ก }}{\stackrel{7}{6}}$

은 ำ

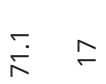

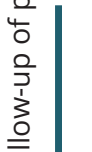

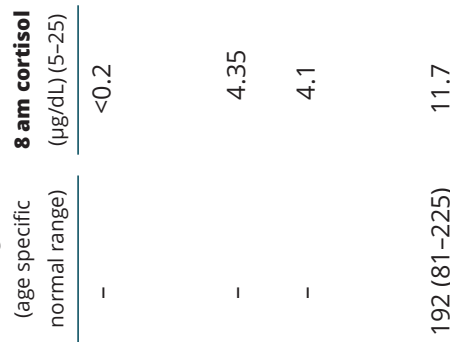

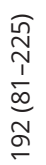

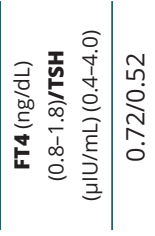

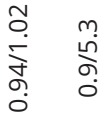

^.

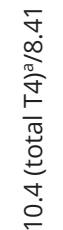

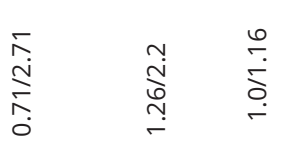

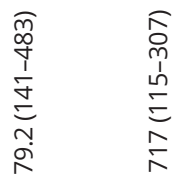

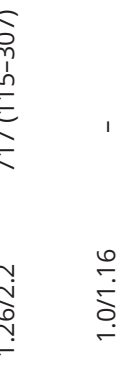

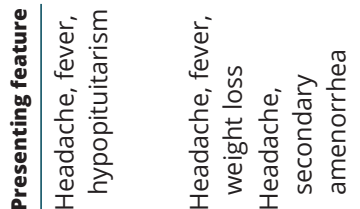

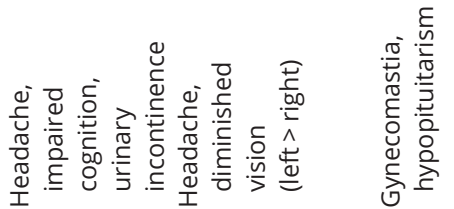

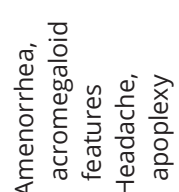

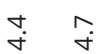

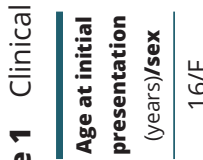

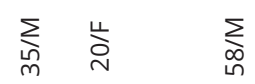

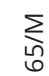

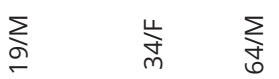

岁 㫕

$\sim m$

$\checkmark$

เก

6

$\wedge \quad \infty$

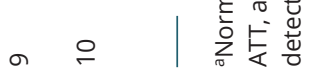


to be the commonest symptom (32.6\%), followed by seizures (26.5\%), cerebral ischaemia (16.3\%), and aseptic meningitis (8.2\%). Our patient (case 4 ) presented with progressive clinical features of hydrocephalus (headache, cognitive impairment, and urinary incontinence) with recent worsening before presentation. MRI scan confirmed the presence of hydrocephalus along with a large lobulated SSR lesion extending posteriorly to interpeduncular and pre-pontine cistern. The mass was hyperintense on T1WI, iso to hypointense on T2WI, and heterogeneously hyperintense on FLAIR with no restriction on DWI (Fig. 2A1, A2, A3 and A4). These are the typical features described for a dermoid cyst (12). Additionally, our patient had multiple small T1W hyperintensities along subarachanoid spaces and in the left lateral ventricle (Fig. 2A1 and A3). This feature is considered pathognomonic of rupture of dermoid cyst (12). In case of a ruptured dermoid cyst, treatment of choice remains a surgical exploration and removal of cyst as much as is possible safely, as recurrence or malignant transformation is very uncommon (11). Unfortunately, our patient declined surgery and did not pursue further treatment. Hence the final histopathology proof could not be obtained, but the MRI features were quite specific to ascribe the diagnosis of ruptured dermoid cyst.
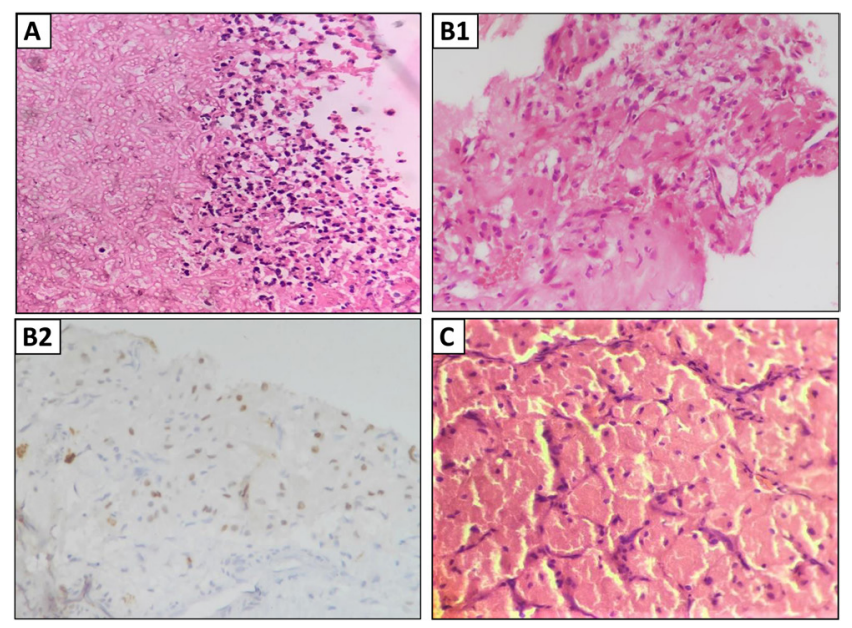

\section{Figure 5}

Photomicrographs showing pathological features of case 3 (Aspergillus abscess) and cases 6 and 7 (Granular cell tumor). Case 3 (Aspergillus abscess): A, aggregates of septate branching filamentous fungi with adjacent degenerating neutrophils (H\&E 400x); Case 6 (Granular cell tumor): B1, tumour showing polygonal cells with abundant eosinophilic granular cytoplasm and central located oval shaped nucleus (H\&E 400x); B2, tumour cells are immunopositive for thyroid transcription factor 1 (TTF1 immunohistochemistry; 400x); Case 7 (granular cell tumor): C, clusters of large cells with abundant granular cytoplasm, small inconspicuous nuclei. Cells are separated by thin walled collapsed vascular channels.

\section{Sellar aneurysm}

Sellar aneurysms are rare, accounting for $1-2 \%$ of all intracranial aneurysms (13). Our patient (case 5) presented with features suggestive of pituitary apoplexy with sudden onset headache, visual deficits, hypocortisolism, and a sellar mass. He was referred to us from another institution after an attempted TSS for a presumed pituitary macroadenoma with apoplexy (details of which could not be ascertained). Careful review of baseline MRI images revealed certain features which were inconsistent with diagnosis of pituitary tumor with apoplexy. The lesion was isointense on T1WI (Fig. 2B1) and had areas of hypointensity on T2WI on left superior aspect (flow voids) and inferior aspect (haemorrhage) (Fig. 2B2). On post contrast imaging, the left superior areas corresponding to flow voids showed intense enhancement while the major part of the mass was not taking up contrast at all (Fig. 2B3), which was a feature unlike that of macroadenoma. Hence a possibility of thrombosed aneurysm was raised and a subsequent digital subtraction angiography confirmed the diagnosis of left supra-clinoid internal carotid artery aneurysm, extending in the sella and displacing optic chiasma. Most part of the aneurysm was occupied by thrombus (Fig. 2B4) and a small patent part which was visible on angiogram. Our case re-iterates several facts about sellar aneurysms reported in literature. In a comprehensive literature review of 40 cases of intrasellar aneurysms, Hanak et al. reported that unruptured aneurysms commonly present with headache $(61 \%)$, visual deficits $(61 \%)$, endocrinopathy (57\%), symptomatic hyponatremia (21\%), and cranial nerve paresis other than optic nerve (18\%) (13). Presentation mimicking pituitary apoplexy, like that in our patient has also been described previously (14). Radiologically, presence of flow voids and onion skin appearance on MRI are considered characteristic for an aneurysm (15). Teng et al. have reported high sensitivity of these features in diagnosis of giant intracranial aneurysms (15). They found sensitivity of $88 \%$ for flow voids on T1WI and T2WI, while onion skin appearance was noted in $80 \%$ of their partially thrombosed aneurysms. Additionally, they found non-enhancement of the thrombus, which was seen in all patients, and intense enhancement of the patent part (specificity 100\%) to be important clues to the diagnosis. Both these features were seen in our patient. Our case highlights the need to consider this differential for a sellar mass as thrombosed aneurysms can be easily mistaken for adenomas, and inadvertent surgery can lead to serious and potentially fatal bleeding complications. Our patient denied any further intervention and so is on conservative management with hormone replacement therapy.

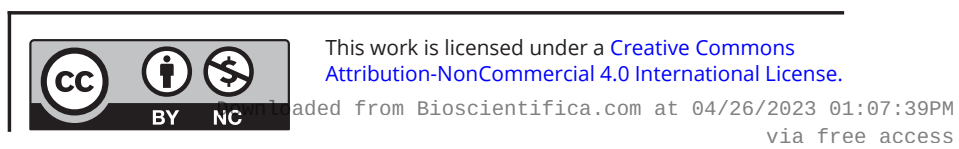




\section{Neoplastic lesions}

\section{Granular cell tumor}

Two patients (cases 6 and 7) in our series have granular cell tumors (GCTs). According to 2017 World Health organisation classification, GCTs are one of the primary posterior pituitary tumors' (PPTs) with proposed origin from pituicytes, the specialised glial cell of neurohypophysis (16). Although small tumorlets are commonly found in autopsy studies, significant enlargement of GCTs to cause symptomatic presentation is rare (17). These patients generally present in fourth to fifth decades with symptoms of mass effect (18). However, one of our patients (case 6) presented early in adolescence period. He had no symptoms of headache or visual disturbance, but presented with features of hypogonadism and gynecomastia. On biochemical evaluation he had pan-hypopituitarism with mild hyperprolactinemia. Another patient (case 7) had headache, amenorrhoea, and clinical features of acromegaly. On hormonal evaluation, she had high IGF1 levels and mild hyperprolactinemia (Table 1). In a recent extensive review including 69 patients with GCTs, Guerrero-Pérez et al. found that hypopituitarism was the most common endocrine manifestation (45\%), but gynecomastia, as seen in our patient (case 6), and DI were rare presentations (18). Both the patients in our cohort did not have DI pre-operatively. Interestingly, hormonal hypersecretion syndrome (as in case 7) is a known but very rare feature of GCTs. In the series by Guerrero-Pérez et al., three patients with GCTs had hypercortisolism, while two had features of acromegaly (18). A co-existing adenoma or secretion of yet un-identified trophic factors by GCTs are the proposed underlying mechanisms for hormonal hypersecretion. GCTs are rarely suspected on pre-operative radiological imaging, as was the case in our patients where diagnosis was established on post-operative histopathology (Fig. 5B1, B2 and C). Covington et al. described that GCTs present either as sellar-suprasellar mass, as in our case 6, (Fig. 3A) or predominantly suprasellar mass with separately seen pituitary, as in our case 7 (Fig. 3B) (19). On MR imaging, they tend to be isointense on both T1WI and T2WI with variable contrast enhancement, features overlapping with that of pituitary adenoma. Non-consideration of the diagnosis pre-operatively does have post-surgical implications as these tumors are often vascular (19). Peri-operative complications are known to be common in GCTs. Both patients in our series developed permanent DI post-operatively, while patient 7 expired in early post-operative period probably due to massive bleed. In their largest series, GuerreroPérez et al. described post-operative DI in one-third of patients, while critical peri-operative bleeding was seen in $20 \%$ of patients with one reported death (18). The role of radiation therapy and any other adjuvant therapies in these tumors is not well established. Patient 6 had a small residual lesion post-surgery, but because of the slow growing nature of these tumors and low Mib1 labelling index on histopathology, he is being observed over time while on hormone replacement.

\section{Pilocytic astrocytoma}

Pilocytic astrocytomas are WHO grade 1 gliomas predominantly seen in children. In the largest series of 27 patients, Deng et al. reported sellar gliomas to be rare, constituting less than $2 \%$ of all CNS gliomas at their centre, $14.8 \%$ of them being pilocytic astrocytoma (20). They found that the commonest presentation was in the first two decades of life, mainly with symptoms of mass effect and endocrine dysfunction. In fact, presentation after 60 years of age was seen in 3.7\% cases only. Our patient (case 8) was unusual and he presented in the seventh decade with apoplexy of the tumor with sudden severe headache during an air travel and consequent hypopituitarism. Another atypical feature seen in our patient was that the tumor was almost entirely intrasellar (Fig. 4A3). With origin from sub-pial astrocytes, astrocyotmas are generally seen on the surface, and cerebellum is the most common location described (21). In SSR, the chiasmatical-hypothalamic origin is common, so that the tumors largely have supra sellar origin with extension into the sella. Purely intra-sellar astrocytomas are extremely rare. Based on experience at their centre and extensive literature search, Parish et al. could compile a series of only four primarily intra-sellar pilocytic astrocytomas (22). Our patient had a solid homogeneous tumor on MRI which was hyperintense on $\mathrm{T} 1$ and isointense on T2 weighted images because of an underlying acute haemorrhage. Contrast enhancement was not visible due to very high baseline intensities (Fig. 4A1, A2 and A3). These tumors are described to be solid, cystic, or both (20). They do not have specific radiological features and are often misdiagnosed as craniophayngiomas (especially in children) (20) or might mimic pituitary macroadenoma in adults (22). With uncertain pre-operative diagnosis, our patient underwent TSS and diagnosis was made on histopathology. Transsphenoidal surgery seems to be a reasonable approach. However, due to invasive growth patterns, complete 
resection can be difficult. Deng et al. reported complete resection to be possible only in $42 \%$ of patients in their series of sellar gliomas (20). Post-operative DI, as seen in our patient, was the most common complication seen in their series, while mean duration of disease free survival was 28 months on long-term follow-up. At 10 months of follow-up, our patient remains on hormone replacement therapy with no tumor residue.

\section{MPNST}

MPNSTs are rare soft tissue sarcomas arising from or differentiating towards the cells of the peripheral nerve sheath. They are proposed to arise de novo in sporadic cases or in pre-existing neurofibroma/schwannoma in neurofibromatosis syndromes or after radiation exposure (23). Our patient (case 9) had a sporadic presentation with no personal or family history of features of NF1 syndrome nor a history of radiation exposure. In a recent extensive series of 280 patients with MPNSTs, Miao et al. described sporadic presentation (65\%) to be more common than NF1 associated (27.5\%) or radiation induced (7.5\%) MPNSTs (23). While extremities and torso are common sites of origin, intracranial MPNSTs are uncommon. Furthermore, reports of sellar MPNSTs, as is the case of our patient, are far from few. To date, less than five cases of sellar MPNSTs are reported $(6,24,25)$. Our patient presented with headache and bitemporal hemianopia. MRI showed a SSR mass which was isointense on T1WI, hyperintense on T2WI, with remarkably intense contrast enhancement (Fig. 4B1, B2 and B3). In a recent series describing MRI features of 16 MPNST patients, Kim et al. reported varying MRI features, none being specific for MPNSTs (26). Thus, in a sporadic setting, missing the pre-operative diagnosis of MPNST is common; however, most of the tumors in their series showed either moderate or marked contrast enhancement, as was seen in our case. Hence, the presence of intense contrast enhancement, though not specific, should raise the consideration of MPNST as one of the differential diagnosis for sellar mass. Our patient underwent surgery and diagnosis was made on characteristic histopathological findings (Fig. 6A1 and A2). He succumbed in early post-operative period, probably due to bleeding complication. The MPNSTs are known to be aggressive tumors with poor prognosis. The prognosis is poorer for NF1 and radiation-associated tumors than sporadic ones (23). Complete resection and use of post-operative radiation therapy seem to be important prognostic determinants.
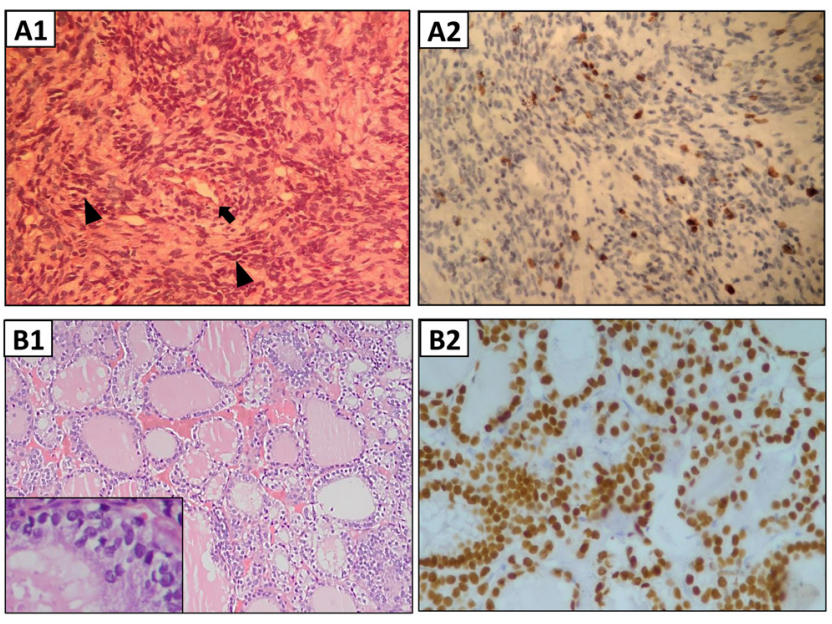

\section{Figure 6}

Photomicrographs showing pathological features of case 9 (Malignant peripheral nerve sheath tumor) and case 10 (Metastasis from papillary thyroid carcinoma). Case 9 (malignant peripheral nerve sheath tumor): A1, tumor with moderate-high cellularity with spindle cells having focally palisading buckled nuclei (black arrowheads) and perivascular condensation of tumor cells (black arrow) (H\&E 400x); A2, tumor showing high proliferative index (MIB-1 index-12\%); Case 10 (metastasis from papillary thyroid carcinoma): B1, tumour showing conspicuous follicular/microfolicular architecture (H\&E 200x) with typical nuclear clearing (as shown in the inset, H\&E 400x); B2, tumour is immunopositive for TTF1 (immunohistochemistry; 400x), thus confirming the primary papillary thyroid carcinoma.

\section{Sellar metastasis}

Our patient (case 10) presented with headache and bitemporal hemianopia. MRI revealed a sellar-suprasellar mass with homogenous contrast enhancement (Fig. 4C). She underwent trans-sphenoidal resection of the mass at another centre, though complete resection was not possible due its hard consistency and adherence to adjacent structures. Histopathology revealed metastasis from papillary thyroid carcinoma (Fig. 6B1 and B2). The subsequent work-up revealed an occult tumor in the thyroid with pulmonary metastasis. She was later referred to our department for management of hypocortisolism and hypothyroidism. She never had clinical evidence of DI. Thyroid surgery, radiotherapy to pituitary metastases, and radioactive iodine therapy for pulmonary metastases were planned. However, she succumbed to rapidly progressive intracranial metastasis within 3 months. Accounting for less than 5\% of all intracranial metastases, pituitary constitutes a rare site for metastasis (27). Recently, Javanbakht et al. reviewed the largest series of 300 patients with pituitary metastasis constituting 11 patients from their centre and 289 patients from world literature (28). Breast cancer followed by lung cancer were the commonest sites of primary

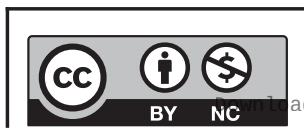

This work is licensed under a Creative Commons Attribution-NonCommercial 4.0 International License. ded from Bioscientifica.com at 04/26/2023 01:07:39PM 


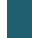

tumor in their series, while thyroid malignancies were third commonest source accounting for approximately $10 \%$ of cases. Posterior pituitary was more commonly involved than anterior pituitary, which was involved only in $27-40 \%$ of cases. First presentation of thyroid malignancy with visual symptoms from SSR metastasis, as in our patient, is a rare but well described feature. In a review of 22 cases of pituitary metastasis from thyroid cancer, Barbaro et al. reported pituitary metastasis to be the first presentation in nine patients (9/22, 40\%) (29). Another peculiar feature in our patient was the absence of DI. In fact, DI is the most common symptom (45\%) when pituitary metastases from all cancers are considered (27). However, it is an uncommon finding in patients with metastases from thyroid cancers and was seen in only two patients $(2 / 22,9 \%)$ in Barbaro et al.'s series (29). The neuro-radiological features are not specific to differentiate SSR metastasis from other lesions, and diagnosis is often made on the basis of histopathology, as was the case in our patient. Neurosurgical intervention is rarely curative due to the adherent and invasive nature of metastases. The adjuvant modalities (after thyroid surgery) include radiation therapy or radioactive iodine therapy. However, the prognosis remains poor especially for larger metastases.

\section{Conclusion}

Most of the rare SSR masses commonly present with symptoms of mass effectsand hypopituitarism. Radiological differentiation of these lesions from other common SSR lesions like adenomas and craniopharyngiomas is often challenging. Although non-neoplastic lesions like sellar abscesses, aneurysms, and dermoid cysts can have some specific imaging characteristics, for most of the neoplastic masses, pre-operative suspicion is difficult. Peri-operative complications tend to be more common. An increased sensitivity for such rare masses is important as it can have significant implications on further surgical and other management strategies.

\section{Declaration of interest}

The authors declare that there is no conflict of interest that could be perceived as prejudicing the impartiality of the research reported.

\section{Funding}

This research did not receive any specific grant from any funding agency in the public, commercial, or not-for-profit sector.

\section{References}

1 Huang BY \& Castillo M. Nonadenomatous tumors of the pituitary and sella turcica. Topics in Magnetic Resonance Imaging 200516 289-299. (https://doi.org/10.1097/01.rmr.0000224685.83629.18)

2 Saeger W, Lüdecke DK, Buchfelder M, Fahlbusch R, Quabbe HJ \& Petersenn S. Pathohistological classification of pituitary tumors: 10 years of experience with the German Pituitary Tumor Registry. European Journal of Endocrinology 2007156 203-216. (https://doi. org/10.1530/eje.1.02326)

3 Freda PU \& Post KD. Differential diagnosis of sellar masses. Endocrinology and Metabolism Clinics of North America 199928 81-117, vi. (https://doi.org/10.1016/S0889-8529(05)70058-X)

4 Fatemi N, Dusick JR, de Paiva Neto MA \& Kelly DF. The endonasal microscopic approach for pituitary adenomas and other parasellar tumors: a 10-year experience. Neurosurgery 200863 (4 Supplement 2) 244-256. (https://doi.org/10.1227/01.NEU.0000327025.03975.BA)

5 Petrakakis I, Pirayesh A, Krauss JK, Raab P, Hartmann C \& Nakamura $M$. The sellar and suprasellar region: a 'hideaway' of rare lesions. Clinical aspects, imaging findings, surgical outcome and comparative analysis. Clinical Neurology and Neurosurgery 2016149 154-165. (https://doi.org/10.1016/j.clineuro.2016.08.011)

6 Abushamat LA, Kerr JM, Lopes MBS \& Kleinschmidt-DeMasters BK. Very unusual sellar/suprasellar region masses: a review. Journal of Neuropathology and Experimental Neurology 201978 673-684. (https:// doi.org/10.1093/jnen/nlz044)

7 Khare S, Lila AR, Patt H, Yerawar C, Goroshi M, Bandgar T \& Shah NS. Gender differences in macroprolactinomas: a single centre experience. Endocrine Connections 20165 20-27. (https://doi. org/10.1530/EC-15-0105)

8 Gao L, Guo X, Tian R, Wang Q, Feng M, Bao X, Deng K, Yao Y, Lian W, Wang R, et al. Pituitary abscess: clinical manifestations, diagnosis and treatment of 66 cases from a large pituitary center over 23 years. Pituitary 201720 189-194. (https://doi.org/10.1007/s11102-016-0757-7)

9 Marzolf G, Sabou M, Lannes B, Cotton F, Meyronet D, Galanaud D, Cottier JP, Grand S, Desal H, Kreutz J, et al. Magnetic resonance imaging of cerebral aspergillosis: imaging and pathological correlations. PLoS ONE 201611 e0152475. (https://doi.org/10.1371/ journal.pone.0152475)

10 Balasundaram P, Garg A, Prabhakar A, Joseph Devarajan LS, Gaikwad SB \& Khanna G. Evolution of epidermoid cyst into dermoid cyst: embryological explanation and radiological-pathological correlation. Neuroradiology Journal 201932 92-97. (https://doi. org/10.1177/1971400918821086)

11 El-Bahy K, Kotb A, Galal A \& El-Hakim A. Ruptured intracranial dermoid cysts. Acta Neurochirurgica 2006148 457-462. (https://doi. org/10.1007/s00701-005-0722-0)

12 Jacków J, Tse G, Martin A, Sąsiadek M \& Romanowski C. Ruptured intracranial dermoid cysts: a pictorial review. Polish Journal of Radiology 201883 e465-e470. (https://doi.org/10.5114/ pjr.2018.80206)

13 Hanak BW, Zada G, Nayar VV, Thiex R, Du R, Day AL \& Laws ER. Cerebral aneurysms with intrasellar extension: a systematic review of clinical, anatomical, and treatment characteristics. Journal of Neurosurgery 2012116 164-178. (https://doi. org/10.3171/2011.9.JNS11380)

14 Torres A, Dammers R \& Krisht AF. Bilateral internal carotid artery aneurysm simulating pituitary apoplexy: case report. Neurosurgery 200965 E1202; discussion E1202. (https://doi.org/10.1227/01. NEU.0000360127.88741.E3)

15 Teng MM-H, Nasir Qadri SM, Luo C-B, Lirng J-F, Chen S-S \& Chang C-Y. MR imaging of giant intracranial aneurysm. Journal of Clinical Neuroscience 200310 460-464. (https://doi.org/10.1016/ S0967-5868(03)00092-4) https://ec.bioscientifica.com https://doi.org/10.1530/EC-19-0497 (c) 2020 The authors Published by Bioscientifica Ltd

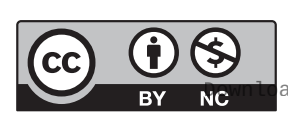

This work is licensed under a Creative Commons Attribution-NonCommercial 4.0 International License. ded from Bioscientifica.com at 04/26/2023 01:07:39PM 
16 Lopes MBS. The 2017 World Health Organization classification of tumors of the pituitary gland: a summary. Acta Neuropathologica 2017 134 521-535. (https://doi.org/10.1007/s00401-017-1769-8)

17 Luse SA \& Kernohan JW. Granular-cell tumors of the stalk and posterior lobe of the pituitary gland. Cancer $19558616-622$. (https://doi.org/10.1002/1097-0142(1955)8:3<616::AIDCNCR2820080327>3.0.CO;2-8)

18 Guerrero-Pérez F, Marengo AP, Vidal N, Iglesias P \& Villabona C. Primary tumors of the posterior pituitary: a systematic review. Reviews in Endocrine and Metabolic Disorders 201920 219-238. (https://doi.org/10.1007/s11154-019-09484-1)

19 Covington MF, Chin SS \& Osborn AG. Pituicytoma, spindle cell oncocytoma, and granular cell tumor: clarification and metaanalysis of the world literature since 1893. American Journal of Neuroradiology 201132 2067-2072. (https://doi.org/10.3174/ ajnr.A2717)

20 Deng S, Li Y, Guan Y, Xu S, Chen J \& Zhao G. Gliomas in the sellar turcica region: a retrospective study including adult cases and comparison with craniopharyngioma. European Neurology 201573 135-143. (https://doi.org/10.1159/000369794)

21 Burkhard C, Di Patre PL, Schüler D, Schüler G, Yaşargil MG, Yonekawa Y, Lütolf UM, Kleihues P \& Ohgaki H. A population-based study of the incidence and survival rates in patients with pilocytic astrocytoma. Journal of Neurosurgery 200398 1170-1174. (https://doi. org/10.3171/jns.2003.98.6.1170)

22 Parish JM, Bonnin JM, Payner TD, Goodman JM \& Cohen-Gadol AA. Intrasellar pilocytic astrocytomas: clinical, imaging, pathological, and surgical findings. Journal of Clinical Neuroscience 201522 653-658. (https://doi.org/10.1016/j.jocn.2014.10.010)
23 Miao R, Wang H, Jacobson A, Lietz AP, Choy E, Raskin KA, Schwab JH, Deshpande V, Nielsen GP, DeLaney TF, et al. Radiationinduced and neurofibromatosis-associated malignant peripheral nerve sheath tumors (MPNST) have worse outcomes than sporadic MPNST. Radiotherapy and Oncology 2019137 61-70. (https://doi. org/10.1016/j.radonc.2019.03.015)

24 Krayenbühl N, Heppner F, Yonekawa Y \& Bernays RL. Intrasellar malignant peripheral nerve sheath tumor (MPNST). Acta Neurochirurgica 2007149 201-205; discussion 205-206. (https://doi. org/10.1007/s00701-006-1080-2)

25 Guo F, Song L \& Meng Y. Malignant peripheral nerve sheath tumour following radiotherapy for pituitary adenoma. Journal of Clinical Neuroscience 201421 184-185. (https://doi.org/10.1016/j. jocn.2013.02.042)

26 Kim HY, Hwang JY, Kim HJ, Kim YK, Cha J, Park GM \& Kim ST. CT, MRI, and 18F-FDG PET/CT findings of malignant peripheral nerve sheath tumor of the head and neck. Acta Radiologica 201758 1222-1230. (https://doi.org/10.1177/0284185116684674)

27 Komninos J, Vlassopoulou V, Protopapa D, Korfias S, Kontogeorgos G, Sakas DE \& Thalassinos NC. Tumors metastatic to the pituitary gland: case report and literature review. Journal of Clinical Endocrinology and Metabolism 200489 574-580. (https://doi. org/10.1210/jc.2003-030395)

28 Javanbakht A, D’Apuzzo M, Badie B \& Salehian B. Pituitary metastasis: a rare condition. Endocrine Connections 20187 1049-1057. (https://doi.org/10.1530/EC-18-0338)

29 Barbaro D, Desogus N \& Boni G. Pituitary metastasis of thyroid cancer. Endocrine 201343 485-493. (https://doi.org/10.1007/s12020012-9806-9)

Received in final form 28 December 2019

Accepted 7 January 2020

Accepted Manuscript published online 7 January 2020 https://ec.bioscientifica.com

https://doi.org/10.1530/EC-19-0497 (c) 2020 The authors Published by Bioscientifica Ltd
This work is licensed under a Creative Commons Attribution-NonCommercial 4.0 International License. ded from Bioscientifica.com at 04/26/2023 01:07:39PM 